\title{
Die Selbstdispensation ist eine Erfolgsgeschichte
}

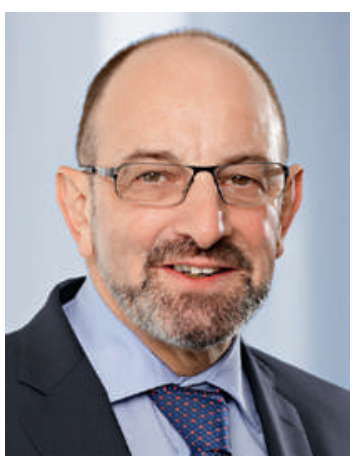

Die ärztliche Medikamentenabgabe ist bei gewissen Parlamentariern und Beamten nach wie vor umstritten. Dies obwohl der Bundesgerichtsentscheid betreffend die Städte Zürich und Winterthur sowie der Abstimmungserfolg im Kanton Schaffhausen ein starkes Plädoyer für die ärztliche Medikamentenabgabe darstellen.

Mit der Revision des Heilmittel- (HMG) und des Medizinalberufegesetzes (MedBG) werden in diesem Jahr wichtige Bundesgesetze angepasst. Bereits im Rahmen der Vernehmlassung zum HMG im Jahr 2010 löste die Forderung des damaligen Bundesrates Pascal Couchepin, die ärztliche Medikamentenabgabe einzuschränken oder abzuschaffen, heftige Empörung aus. Ein solches Ansinnen widerspricht dem Volkswillen und ist hinsichtlich der Gesundheitskosten kontraproduktiv. Die erfolgreiche Abstimmung im Kanton Schaffhausen von vergangenem November zeigte erneut, dass das Volk Medikamente auch beim Arzt beziehen will, 71,5\% der Stimmbürger haben sich für eine Abgabe auch in den Städten Schaffhausen und Neuhausen ausgesprochen. $\mathrm{Zu}$ diesem hervorragenden Ergebnis gratuliere ich der Ärztegesellschaft des Kantons Schaffhausen herzlich und bedanke mich für den grossen Einsatz!

\section{Das Volk will Medikamente auch beim Arzt beziehen.}

Auch der grosse Einsatz der Ärztegesellschaft des Kantons Zürich wurde belohnt. Nach drei gewonnenen Abstimmungen, diversen Rechtsverfahren sowie einem wichtigen Bundesgerichtsentscheid im vergangenen Jahr ist die ärztliche Medikamentenabgabe per 1. Mai 2012 nun auch in den Städten Zürich und Winterthur gesichert. Der Kanton Zürich ist somit der 14. Kanton, in dem die Selbstdispensation (SD) uneingeschränkt zulässig ist, Schaffhausen wird bald schon der 15. sein. In den Kantonen Bern und Graubünden ist die SD bereits teilweise zulässig. In der Deutschschweiz kennen einzig die Kantone Basel-Stadt und Aargau die SD noch nicht.

Nicht nur in der Schweiz, sondern auch in verschiedenen Ländern Europas ist die Abgabe von Medikamenten in der Arztpraxis möglich. Auch bei den deutschen Hausärzten wird immer intensiver über eine direkte Medikamentenabgabe in der Arztpraxis diskutiert. Die Delegiertenversammlung des Deutschen Hausärzteverbandes beauftragte den Vorstand im September 2012, die Einführung der SD ernsthaft zu prüfen. Mehr dazu erfahren Sie in dieser Ausgabe der Schweizerischen Ärztezeitung auf Seite 55.

Santésuisse behauptete an einer Medienkonferenz im Oktober 2012, dass selbstdispensierende Ärzte sowohl über den TARMED als auch über die Marge entschädigt würden. Zudem seien die Logistikkosten der Medikamentenabgabe im TARMED enthalten. Diese Darstellung von santésuisse ist unqualifiziert, unzutreffend und falsch. Sie rief, wie kaum

\section{Die ärztliche Medikamentenabgabe ist kostengünstig.}

anders zu erwarten war, auch die Apotheker für eine polemische Attacke gegen die SD und die Ärzteschaft auf den Plan. Die FMH konnte diese Falschmeldung der Krankenversicherer anhand der Dokumentation des TARMED eindeutig widerlegen. Santésuisse hat mit ihrer Aussage einen unnötigen Schaden angerichtet und die fachliche Sorgfalt vernachlässigt.

Die Abgeltung sowohl der ärztlichen Leistung als auch der Logistikkosten bei der Medikamentenabgabe erfolgt nachweislich allein über die staatlich verordnete Marge. Ein «Doppelverdienst» wie beispielsweise bei den Apothekern über die leistungsorientierte Abgabe (LOA) findet bei den Ärzten nicht statt. Die ärztliche Medikamentenabgabe ist aber auch bezüglich der Kosten zu favorisieren, sind doch die Medikamentenkosten pro versicherte Person bei den Selbstdispensationskantonen am tiefsten. Nicht berücksichtigt sind bei diesem Vergleich die zusätzlichen Kosten der LOA der Apotheker.

Die Selbstdispensation ist nach zahlreichen parlamentarischen Beratungen und kantonalen Volksabstimmungen weiterhin ein breitabgestütztes Erfolgsmodell, das von der Bevölkerung gefordert wird sowie patientenfreundlich und kostengünstig ist. An diesem Erfolgsmodell zu rütteln, wäre ein Angriff auf den Volkswillen und den Föderalismus!

Dr. med. Ernst Gähler,

Vizepräsident FMH und Verantwortlicher Ressort Ambulante Tarife und Verträge Schweiz 